\title{
Evaluation of satellite based indices for gross primary production estimates in a sparse savanna in the Sudan
}

\author{
M. Sjöström ${ }^{1}$, J. Ardö ${ }^{1}$, L. Eklundh ${ }^{1}$, B. A. El-Tahir ${ }^{2}$, H. A. M. El-Khidir ${ }^{2}$, M. Hellström ${ }^{1}$, P. Pilesjö ${ }^{1}$, and J. Seaquist ${ }^{1}$ \\ ${ }^{1}$ Department of Physical Geography and Ecosystem Analysis, Lund, Sweden \\ ${ }^{2}$ Agricultural Research Corporation, El Obeid, Sudan
}

Received: 25 June 2008 - Published in Biogeosciences Discuss.: 29 July 2008

Revised: 17 December 2008 - Accepted: 17 December 2008 - Published: 29 January 2009

\begin{abstract}
One of the more frequently applied methods for integrating controls on primary production through satellite data is the Light Use Efficiency (LUE) approach. Satellite indices such as the Normalized Difference Vegetation Index (NDVI), Enhanced Vegetation Index (EVI) and the Shortwave Infrared Water Stress Index (SIWSI) have previously shown promise as predictors of primary production in several different environments. In this study, we evaluate NDVI, EVI and SIWSI derived from the Moderate Resolution Imaging Spectroradiometer (MODIS) satellite sensor against in-situ measurements from central Sudan in order to asses their applicability in LUE-based primary production modeling within a water limited environment. Results show a strong correlation between vegetation indices and gross primary production (GPP), demonstrating the significance of vegetation indices for deriving information on primary production with relatively high accuracy at similar areas. Evaluation of SIWSI however, reveal that the fraction of vegetation apparently is to low for the index to provide accurate information on canopy water content, indicating that the use of SIWSI as a predictor of water stress in satellite data-driven primary production modeling in similar semi-arid ecosystems is limited.
\end{abstract}

\section{Introduction}

With the emergence of international environmental treaties such as United Nations Framework Convention on Climate Change (UNFCCC) and its Kyoto Protocol, there is an urgent

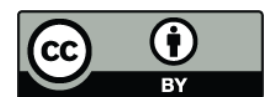

Correspondence to: $\mathrm{M}$. Sjöström (martin.sjostrom@nateko.lu.se) need to quantify the global carbon budget and its temporal and spatial variations (IPCC, 2007). One of the least wellcovered regions by studies on carbon dynamics and climate change is Africa, a continent with widespread poverty and slow economic development (Giles, 2007).

Droughts and famines frequently impact the people living in the African Sahel, a semi-arid grass- and shrubland region located south of the Saharan desert. The region has recently been flagged as a hotspot for climatic change as findings from polar orbiting satellites reveal a widespread increase in vegetation greenness (Eklundh and Olsson, 2003; Herrmann et al., 2005; Seaquist et al., 2006). This observed greening has partly been explained by variations in rainfall (Hickler et al., 2005) and could represent part of the residual terrestrial carbon sink (Houghton, 2003). Knowledge on primary production in this region is therefore of key importance, both in the light of the climatic fluctuations that have occurred in this region over the last decades (Hulme, 2001) and considering the predicted effects of climate change (IPCC, 2007).

Photosynthesis, the process by which plants harvest solar energy and carbon needed for ecosystem maintenance, is key to determining ecosystem primary production, the net amount of carbon captured by land living plants (Hanan et al., 1998). Most existing estimates of primary production at continental to global scales have been made with the use of sophisticated process-based ecosystem models driven mainly by climate data (Sitch et al., 2003). However, during the last decade, rapid developments in satellite sensor technology have allowed remote sensing based primary production models to emerge as an attractive approach. Considering the spatial and temporal variations of the processes related to plant growth, repetitive and accurate satellite based measurements may contribute significantly to our knowledge on vegetation dynamics and responses to changing

Published by Copernicus Publications on behalf of the European Geosciences Union. 


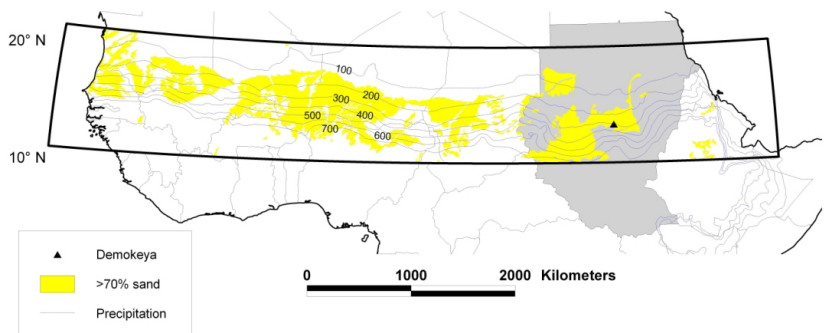

Fig. 1. Map showing the location of the study area in central Sudan. Yellow denotes areas of $>70 \%$ sand whereas isohyets show mean annual rainfall in $\mathrm{mm}$.

environmental conditions. The improved spatial and spectral resolution of satellite sensors such as the Moderate Resolution Imaging Spectroradiometer (MODIS), in comparison to the extensively used Advanced Very High Resolution Radiometer (AVHRR), has further allowed a reassessment of the potential for modeling primary production solely by the use of satellite data.

One of the more widely applied concepts within the domain of satellite based primary production models is the Light Use Efficiency (LUE) approach, first described by Monteith $(1972,1977)$. Here GPP, the Gross Primary Production related to the carbon assimilated by plants is expressed as:

$\mathrm{GPP}=\varepsilon \times \mathrm{PAR} \times \mathrm{fPAR}$

where $\varepsilon$ is the conversion efficiency, PAR is incoming photosynthetically active radiation in the wavelengths $400-700 \mathrm{~nm}$ and PPAR represents the fraction of PAR absorbed by the canopy. fPAR is generally estimated through the use of spectral vegetation indices such as the Normalized Difference Vegetation Index (NDVI) (Daughtry et al., 1983; Asrar et al., 1984; Sellers et al., 1994) and the Enhanced Vegetation Index (Xiao et al., 2004) whereas the PAR received at the Earth's surface can be estimated by interpolating point measurements from light sensors or be derived from the use of Earth observation data (Eck and Dye, 1991; Seaquist and Olsson, 1999; Van Laake and Sanchez-Azofeifa, 2005; Liang et al., 2006; Olofsson et al., 2007b). The conversion efficiency factor $\varepsilon$ was originally regarded as a fixed empirical constant when first introduced (Monteith, 1972) but during the past decade it has become more common to estimate or scale $\varepsilon$ using models or satellite retrievals. Numerous stress factors control $\varepsilon$ and estimating this critical parameter can be difficult due to high spatial and temporal variability inherent to site specific and meteorological conditions (Hilker et al., 2008).

In semi-arid environments such as the Sahel, water is generally the most limiting factor for growth, and numerous satellite sensor-based primary production studies have focused on model-based derivation of information related to plant water stress in order to scale $\varepsilon$ (Nemani and Running,
1989; Field et al., 1995; Prince and Goward, 1995; Seaquist et al., 2003). Progress has also recently been made using satellite data to detect canopy water stress (Ceccato and Flasse, 2002; Ceccato et al., 2002; Fensholt and Sandholt, 2003; Xiao et al., 2004). However, further work is required to strengthen our knowledge regarding indices related to water stress as well as their applicability for estimating primary production using satellite remote sensing.

In this paper, we aim to test satellite-based variables that can be used to upscale estimates of fluxes of $\mathrm{CO}_{2}$ in semi-arid Sahel by comparing these against site-specific measurements from central Sudan. We further investigate the applicability of these variables by including them in a simple parametric LUE-model, a model that should be regarded merely as a point of progress for future proceedings on satellite datadriven primary production modeling in semi-arid regions.

\section{Study area and instrumentation}

\subsection{Study area}

The flux tower used in this study is located at the village Demokeya $\left(13.3^{\circ} \mathrm{N}, 30.5^{\circ} \mathrm{E}\right)$ in Northern Kordofan state in central Sudan, approximately $35 \mathrm{~km}$ northeast of the state capital El Obeid (Fig. 1). Soils in the area are mainly sandy and vegetation at the site consists primarily of sparse Acacia senegal savanna with a canopy cover of 5-10\%, and a ground cover composed mainly of $\mathrm{C}_{4}$ grasses and herbs, mainly Aristida pallida, Eragrostis tremula and Cenchrus biflorus. Mean annual precipitation is about $320 \mathrm{~mm}$ and generally falls from June-October, and the mean annual temperature is around $26^{\circ} \mathrm{C}$. The deep sandy soil (96.5\% sand and 3.5\% silt) has estimated minimum (wilting point) and maximum (field capacity) water holding capacities of 5\% and $15 \%$ respectively, and hence a maximum plant available water content of around $10 \%$. The landscape is gently undulating due to stabilized parallel sand dunes with a N-S orientation.

\subsection{Instrumentation}

Fluxes of $\mathrm{CO}_{2}\left(\mathrm{FCO}_{2}\right), \mathrm{H}_{2} \mathrm{O}\left(\mathrm{FH}_{2} \mathrm{O}\right)$ and energy were measured with the eddy covariance technique according to the EUROFLUX methodology (Aubinet et al., 2000). Measurements were performed at $20 \mathrm{~Hz}$ using an open path eddy covariance system (In Situ Flux Systems AB, Sweden) and stored as 30-min averages. Instruments include a LI7500 (LiCor, Lincoln, US) open-path infrared $\mathrm{CO}_{2}$ and $\mathrm{H}_{2} \mathrm{O}$ gas analyzer and a GILL R3 Ultrasonic Anemometer (GILL Instruments, UK) mounted $9 \mathrm{~m}$ above the ground, approximately $4 \mathrm{~m}$ above the sparse canopy.

Located approximately $400 \mathrm{~m}$ from the flux tower is a separate climate station that measures temperature, relative humidity, precipitation, wind and global radiation using standard equipment. Additional measurements at this station 
include soil moisture (TDR, CS615/CS616, Campbell Scientific, US) and soil temperature (soil temperature probe 107/108, Campbell Scientific, US) measured at a depth of $5 \mathrm{~cm}$, net radiation (NR-Lite, Kipp and Zonen, US) and incoming PAR (JYP1000, SDEC, France).

\section{Data and methods}

\subsection{Eddy covariance data}

The carbon budget is described by three components: i) gross primary productivity (GPP), the carbon captured through photosynthesis; ii) net ecosystem exchange (NEE), the net exchange of carbon between the ecosystem and atmosphere; iii) and ecosystem respiration $\left(R_{\text {eco }}\right)$, which is the sum of plant and heterotrophic respiration. NEE, GPP and $\mathrm{R}_{\mathrm{eco}}$ were derived from half-hourly values of $\mathrm{CO}_{2}$ from July to December for the 2007 season (data prior to July were not available).

In order to obtain seasonal estimates of $\mathrm{CO}_{2}$ exchange, eddy covariance data was gap-filled according to the method used by Reichstein et al. (2005) (amount of gaps was 39\% for the period). This method considers both the covariance between fluxes as well as meteorological drivers and temporal structure.

Previous studies from the Sahel have shown that soil respiration not only depends on temperature but also on the amount of available water (Friborg et al., 1997; Hanan et al., 1998). In order to account for the soil water dependency, $R_{\text {eco }}$ was estimated by using the exponential regression model of Lloyd and Taylor (1994) in combination with a soil water content factor $\left(\mathrm{F}_{w}\right)$ derived from volumetric soil moisture (Wang and Leuning, 1998):

$F_{w}=\min \left(1, \frac{10\left(\theta-\theta_{\text {Min }}\right)}{3\left(\theta_{\text {Max }}-\theta_{\text {Min }}\right)}\right)$

where $\theta$ is the actual soil water content in the upper soil layer $(5 \mathrm{~cm}), \theta_{\min }$ and $\theta_{\max }$ are the minimum and maximum soil water content respectively. Using typical values for sandy soils, $\mathrm{F}_{w}$ is thus scaled between wilting point and field capacity (i.e. approximately 5 and 15\%) and the effects of the amount of available water on $\mathrm{R}_{\text {eco }}$ are taken in account by integrating $\mathrm{F}_{w}$ with the Lloyd and Taylor (1994) expression:

$R_{\mathrm{eco}}=F_{w} R_{10} e^{308.56\left(\frac{1}{56.02}-\frac{1}{T_{\mathrm{soil}}-227.15}\right)}$.

Daytime GPP was estimated as GPP $=R_{\text {eco }}-\mathrm{NEE}$, whereas nighttime GPP was set equal to zero based on a global radiation threshold of $20 \mathrm{Wm}^{-2}$.

\subsection{Eddy covariance footprint}

When verifying remote sensing based indices against insitu flux measurements it is important to determine the extent of the surface footprint of flux tower measurements to determine the area over which reflectance data are to be obtained. A two-dimensional analytical footprint model, FSAM (Schmid, 1994), was used to approximate the source area contributing to the $\mathrm{CO}_{2}$ flux measurements. For each half-hourly value during the 2007 growing season, source area functions dependent on atmospheric stability and surface roughness were calculated in order to estimate the spatial scale of measurements. Input parameters required to run the model are the effective height $(\mathrm{z})$; surface roughness length $\left(\mathrm{z}_{0}\right)$; Obukhov length $(L)$; friction velocity $(u *)$ and crosswind turbulence intensity $\left(\sigma_{v /} u *\right) . L, \sigma_{v}$ (standard deviation of lateral wind speed fluctuations) and $u *$ were derived from half-hourly sonic anemometer data wheras $\mathrm{z}_{0}$ was set to $0.5 \mathrm{~m}$ based on Wieringa (1993). Footprint functions were then rotated based on the prevailing wind direction and further projected onto a $2 \times 2 \mathrm{~km}$ grid plane with the flux tower at its centre.

\subsection{Satellite data}

We used satellite data from the MODIS/EOS Terra product MOD09A1, which provides an estimate of surface spectral reflectance in seven bands as it would have been measured at the ground (Vermote et al., 2002). The MOD09A1 surface reflectance product includes correction for the effects of aerosols, thin cirrus clouds and atmospheric gases and serves as an input for several higher order land products such as fPAR/LAI and vegetation indices. The spatial resolution of the MOD09A1 data set is $500 \mathrm{~m}$ and data is composed of the best observations during 8-day periods with regards to overall pixel quality and observational coverage (Justice et al., 2002).

Spectral vegetation indices used to monitor vegetation are usually composed of reflectances from the red $\left(\rho_{\text {red }}\right)$ and Near Infrared (NIR, $\rho_{\text {nir }}$ ) wavelengths (Tucker, 1979) such as the NDVI which is defined as:

$$
N D V I=\frac{\rho_{\text {nir }}-\rho_{\text {red }}}{\rho_{\text {nir }}+\rho_{\text {red }}}
$$

Early studies used NDVI as a surrogate measure of primary production, applying an integrated approach over the entire growing season to estimate primary productivity (Tucker et al., 1983; Tucker et al., 1985). Numerous studies have since then appeared, implementing a linear relationship between fPAR and NDVI to approximate primary production (Daughtry et al., 1983; Asrar et al., 1984; Sellers et al., 1994; Seaquist et al., 2003; Olofsson et al., 2007a). NDVI has, however, been reported to be sensitive to differences in background reflectance and to saturate for areas of high biomass (Huete et al., 1997). The Enhanced Vegetation Index (EVI) was developed to enhance the vegetation signal by reducing influences from the atmosphere and canopy background and to improve sensitivity in high biomass regions (Huete et al., 1997; Huete et al., 2002). As with the NDVI, EVI is estimated from surface reflectance in the red and NIR bands 
but it also uses reflectance in the blue band ( $\left.\rho_{\text {blue }}\right)$ to correct for effects of aerosols. Using surface reflectance data from MODIS, EVI is calculated as:

$$
E V I=2.5 \times \frac{\rho_{\text {nir }}-\rho_{\text {red }}}{\rho_{\text {nir }}+\left(6 \times \rho_{\text {red }}-7.5 \times \rho_{\text {blue }}\right)+1}
$$

Several studies have previously revealed a good general relationship between EVI and GPP (Xiao et al., 2004; Rahman et al., 2005; Sims et al., 2006b; Olofsson et al., 2008). Building on this, Sims et al. (2008) developed a temperature and greenness model solely based on the MODIS Land Surface Temperature (LST) and EVI products. Modeled GPP estimates were in good agreement with measured values, highlighting EVI's potential for use as a predictor of GPP, and further demonstrating that GPP can be estimated with relatively high accuracy using only remote sensing data.

In the Sahel region, water is generally assumed to be the limiting factor for photosynthesis and several attempts have previously been made at developing satellite-based stress factors that account for canopy or soil water deficits (Gao, 1996; Ceccato and Flasse, 2002; Ceccato et al., 2002; Fensholt and Sandholt, 2003). The Short-wave Infrared (SWIR, $\rho_{\text {swir }}$ ) and NIR bands available on the MODIS sensor present opportunities to quantify equivalent water thickness (EWT), a term denoting spectral absorption resulting from the leaf water content. One possibility to derive information on canopy water stress through the use of MODIS satellite data is the Short wave Infrared Water Stress Index (SIWSI) based on NIR and SWIR band 6 reflectance (Fensholt and Sandholt, 2003):

SIWSI $=\frac{\rho_{\text {nir }}-\rho_{\text {wir }}}{\rho_{\text {nir }}+\rho_{\text {swir }}}$

Fensholt and Sandholt (2003) tested two configurations of SIWSI based on surface reflectance in the NIR, band 5 $(1230-1250 \mathrm{~nm})$ and band $6(1628-1652)$ and found that the NIR and SWIR band 6 combination performed slightly better when compared against modeled and measured soil moisture in semi-arid Senegal. As can be seen in Eq. (6), SIWSI is a normalized index with values theoretically ranging between -1 and 1 . As the water content increases, the reflectance in the SWIR diminishes. A high SIWSI value would therefore indicate sufficient amounts of water whereas, a low value would indicate water stress.

We acquired the MOD09A1 8-day product from Earth Observing Systems Data Gateway (EDG, http://edcimswww. cr.usgs.gov/pub/imswelcome/) for the year 2007. The grid plane with integrated eddy covariance source area functions generated through the footprint model was geometrically corrected and superimposed with the MODIS satellite data in order to determine which pixels to include in the analysis. In addition to the tower pixel, three pixels adjacent to the tower pixel were found to fall within the footprint of the flux tower. Data for surface reflectance were thus extracted for a $1 \times 1 \mathrm{~km}$ area and then used to calculate NDVI, EVI and SIWSI according to Eqs. (4), (5) and (6). In order to minimize the effects of sensor disturbances, the estimated NDVI and EVI time series were seasonally adjusted by an adaptive Savitzky-Golay filtering method using the TIMESAT program package (Jönsson and Eklundh, 2002, 2004). TIMESAT fits a function to the upper envelope of the satellite time series data, effectively filtering out negatively biased noise due to, for instance, atmospheric effects (Eklundh and Olsson, 2003; Olofsson et al., 2008).

\subsection{LUE-model}

In order to further assess the applicability of satellite-based measurements we incorporated MODIS indices in a simple parametric LUE-model formulated as follows:

$\mathrm{GPP}=\varepsilon_{p} \times \varepsilon \times \mathrm{fPAR} \times \mathrm{PAR}$,

where $\varepsilon_{p}$ represents the maximum biological efficiency of PAR conversion to dry matter ( $\left.\mathrm{g} \mathrm{C} \mathrm{mol}^{-1} \mathrm{PAR}\right)$.

Most herb layers in the Sahel region consist of a combination of $\mathrm{C}_{3}$ and $\mathrm{C}_{4}$ species, where $\mathrm{C}_{3}$ often dominates in the early part of the growing season (Hanan and Prince, 1997). We therefore prescribed a fixed value of $0.489 \mathrm{~g} \mathrm{C} \mathrm{mol}^{-1}$ PAR for $\varepsilon_{p}$ (Seaquist et al., 2003; Seaquist et al., 2006), which indicates a mixture of $\mathrm{C}_{3}$ and $\mathrm{C}_{4}$ plants with the assumption that $\mathrm{C}_{4}$ grasses dominate for the greater part of the growing season.

SIWSI was linearly scaled as $\varepsilon$ using maximum and minimum values during the 2007 season to assess its potential as an estimator of maximum light use efficiency. The index has previously been shown to increase predictions of above ground net primary production in the semi-arid Sahel (Fensholt et al., 2006).

Vegetation indices have been shown to be highly correlated with processes that are dependent on light absorption (Daughtry et al., 1983; Asrar et al., 1984; Sellers et al., 1994; Huete et al., 2002; Xiao et al., 2004; Rahman et al., 2005; Sims et al., 2006b; Olofsson et al., 2008) and are represented as fPAR in Eq. (7) whereas the PAR component, in turn, represents 8-day sums of measurements from the climate station in order to be consistent with the temporal resolution of the MOD09A1 product.

\section{Results}

4.1 Seasonal variation in carbon exchange, climate and EVI

Figure 2a shows day-to-day variation in GPP, NEE and $\mathrm{R}_{\text {eco }}$ from July to December 2007, whereas Fig. 2b shows cumulative fluxes together with aboveground net primary production (AGNPP) assessments of herbs and grasses (negative 


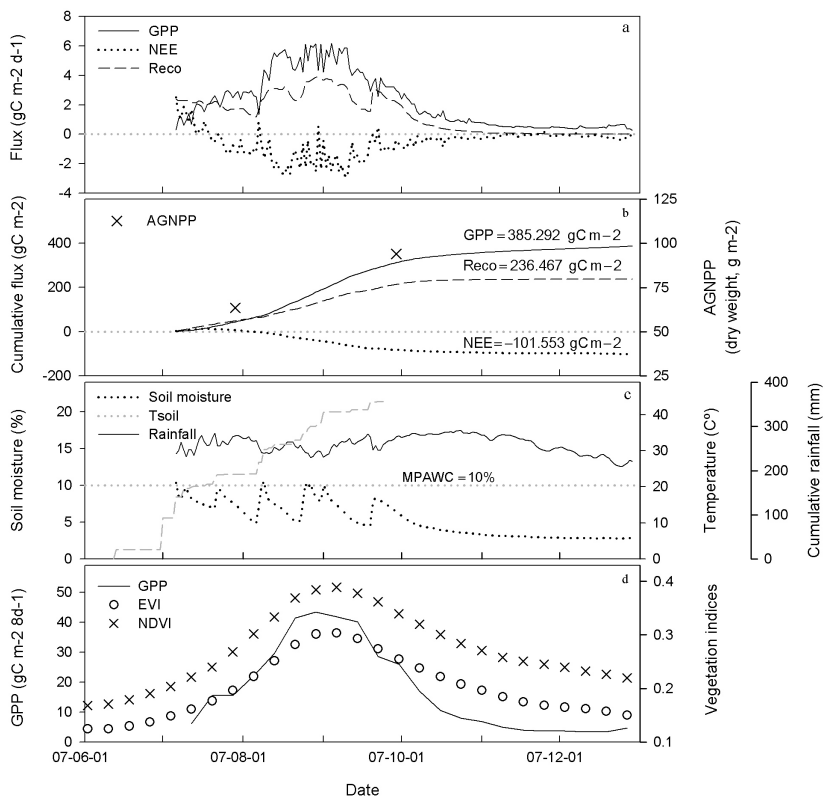

Fig. 2. Seasonal patterns of (a) daily eddy covariance GPP, NEE and $\mathrm{R}_{\mathrm{eco}}$, (b) cumulative GPP, NEE, $\mathrm{R}_{\mathrm{eco}}$ and assessments of above ground biomass, (c) measured daily average soil temperature $(5 \mathrm{~cm})$, soil moisture $(5 \mathrm{~cm})$ and cumulative rainfall (dotted gray line denotes maximum plant-available water content at $10 \%$ soil moisture) and (d) 8-day sums of eddy covariance GPP plotted against 8-day values of MODIS EVI and NDVI for the Demokeya site from June to 31 December 2007.

values denote net ecosystem $\mathrm{CO}_{2}$ uptake). Net uptake increases as conditions gradually become more favourable for plant growth with the onset of the rain in June (Fig. 2c). Total annual rainfall for the 2007 season was $364 \mathrm{~mm}$, which is slightly higher than the annual average of $320 \mathrm{~mm}$ and noticeably higher compared to previous season as Demokeya received a total of $273 \mathrm{~mm}$ in 2006. Peak uptake occurs in late August and early September. GPP and $\mathrm{R}_{\text {eco }}$ decline rapidly as soil water content decreases with the last rains falling on 22 September (Fig. 2c).

The seasonal progression of TIMESAT-adjusted MODIS vegetation indices is shown in Fig. 2 d. The site shows a distinct seasonal variation in NDVI and EVI which corresponds rather well to the seasonal dynamics of 8-day sums of GPP.

\subsection{GPP relationships and modeling}

Linear regressions between EVI and NDVI against GPP were computed, with the results being shown in Fig. 3. A strong linear relationship was observed (Fig. 3). EVI performed marginally better than NDVI with the coefficient of determination, $R^{2}=0.93$ and $\mathrm{RMSE}=3.96 \mathrm{C} \mathrm{m}^{-2} 8 \mathrm{~d}^{-1}$ (Table 1). We also performed a linear regression between vegetation indices and GPP using the tower pixel and its eight surrounding pixels. Correlations were found to be slightly weaker, with $R^{2}=0.89$ and $R^{2}=0.87$ for EVI and NDVI respectively.
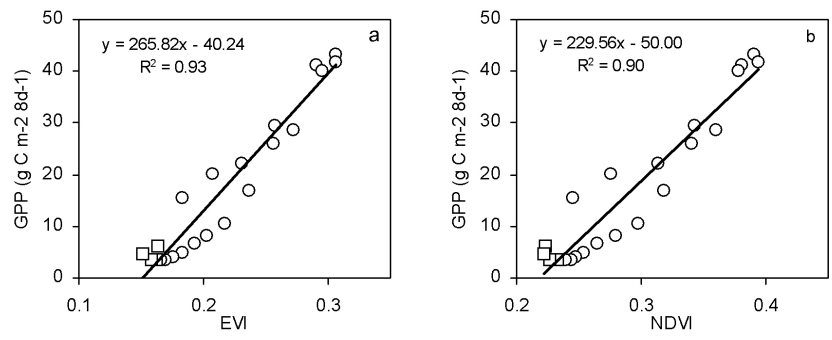

Fig. 3. Linear regression analysis between 8-day sums of eddy covariance GPP and (a) MODIS EVI and (b) MODIS NDVI for the Demokeya site 2007, July-December (squares denote points outside the growing season).

Table 1. Linear regression and multiple linear regression statistics with observed GPP as dependant variable (number of observations=22).

\begin{tabular}{lrcccc}
\hline $\begin{array}{l}\text { Independent } \\
\text { variable(s) }\end{array}$ & B0 & B1 & B2 & R2 & $\begin{array}{c}\text { RMSE } \\
\left(\mathrm{g} \mathrm{C} \mathrm{m}^{-2} 8 \mathrm{~d}^{-1}\right)\end{array}$ \\
\hline EVI & -40.24 & 265.82 & - & 0.93 & 3.93 \\
NDVI & -50.00 & 229.56 & - & 0.90 & 4.58 \\
SIWSI & 39.55 & 272.63 & - & 0.87 & 5.39 \\
EVI, $\varepsilon$ & -34.33 & 213.19 & 12.56 & 0.93 & 3.91 \\
Modeled GPP & 0.70 & 0.94 & - & 0.88 & 5.22 \\
\hline
\end{tabular}

Furthermore, a strong relationship between SIWSI and GPP was detected with $R^{2}=0.87$ and $\mathrm{RMSE}=5.39 \mathrm{C} \mathrm{m}^{-2}$ $8 \mathrm{~d}^{-1}$ (Table 1). This is not surprising as an overall relation between vegetation intensity and water availability, as observed by satellite, could be expected. However, Fensholt and Sandholt (2003) found SIWSI to be highly correlated with NDVI, indicating a redundancy between SIWSI and MODIS vegetation indices. A comparison between NDVI, EVI and SIWSI was subsequently performed (Fig. 4). With time series fluctuations occurring at practically the same pace, results showed that there was a significant redundancy between 8-day vegetation indices and SIWSI for this specific site with $R^{2}=0.92$ for EVI (Fig. 4 a) and $R^{2}=0.90$ for NDVI (Fig. 4b).

We further assessed SIWSI's potential as an estimator of water stress by testing the index against measurements of soil moisture at a depth of $5 \mathrm{~cm}$ (Fig. 5). Although it can be argued that superficial soil moisture can be regarded as a surrogate measure of EWT, only a weak relationship $\left(R^{2}=0.50\right)$ with a RMSE of $1.58 \%$ was observed. It is also apparent in Fig. (5) that the correlation is mainly attributed to dry season measurements. Additionally, it was also observed that both MODIS vegetation indices were stronger correlated to soil moisture with a $R^{2}$ of 0.61 and a RMSE of $1.39 \%$ for EVI, and a $R^{2}$ of 0.58 and RMSE of $1.44 \%$ for NDVI. 

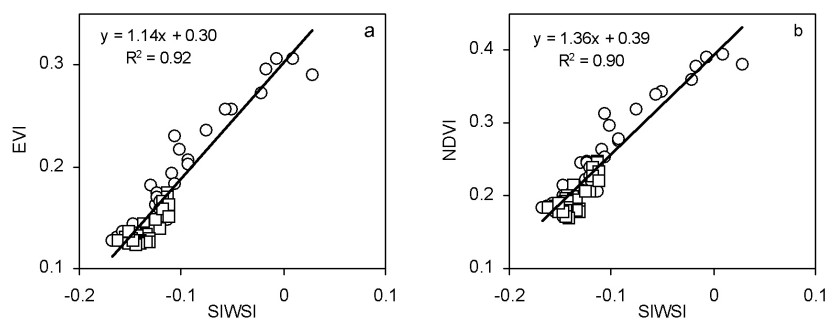

Fig. 4. Linear regression analysis between 8-day values of MODIS SIWSI and (a) MODIS EVI and (b) MODIS NDVI for the Demokeya site 2007, January-December (squares denote points outside the growing season).

As previously stated, EVI, NDVI and SIWSI preformed well when compared against 8-day sums of GPP (Fig. 3, Table 1). The NDVI time series data, however, had a marginally weaker linear relationship with observed GPP than the EVI time series and was therefore excluded from further analysis. Additional analysis, by means of multiple linear regression, was thus performed using EVI and $\varepsilon$ as independent variables in order to test the implications of including $\varepsilon$ as a predictor of GPP. Results showed that $\varepsilon$ did not add further significant explanation to the observed variance of GPP values (Table 1).

Figure 6 shows 8-day modeled GPP at Demokeya with observed 8-day sums from July to December 2007. Modeled GPP was calculated for every 8-day period according to Eq. (7) assuming a 1:1 relationship between EVI and fPAR. As shown in Fig. 7, the seasonal dynamics of modeled GPP agreed rather well with measured GPP $\left(R^{2}=0.88\right)$, with cumulative sums over the modeled period July 12 to December 27 differing by $6.70 \%$ (Fig. 6b). The data points are described by the equation $\mathrm{GPP}_{\mathrm{obs}}=0.94 \mathrm{GPP}_{\bmod }-0.07$, which is close to a 1:1 line (Fig. 7). However, the model fails at the beginning of the growing season with the remaining variance in the measured versus modeled data $\left(5.22 \mathrm{~g} \mathrm{C} \mathrm{m}^{-2} 8 \mathrm{~d}^{-1}\right.$, Table 1) mainly originating from the effects of $\varepsilon$.

\section{Discussion}

The aim of this study involved assessing the applicability of three satellite-based indices from MODIS data (EVI, NDVI and SIWSI) for primary production modeling in a semi-arid environment in the Sahel. Indices were tested through comparison with site-specific measurements of $\mathrm{CO}_{2}$ fluxes from central Sudan. In order to evaluate the applicability of satellite indices, flux tower measurements of NEE were used to derive GPP. Soil moisture and soil temperature are usually regarded as being the primary environmental factors controlling $\mathrm{R}_{\mathrm{eco}}$ in semi-arid environments, and hence $\mathrm{R}_{\mathrm{eco}}$ was estimated by using a soil water content factor, representing the relative availability of soil water for plants (Wang and Leuning, 1998) together with the exponential regression model of Lloyd and Taylor (1994). This step is critical, as accurate

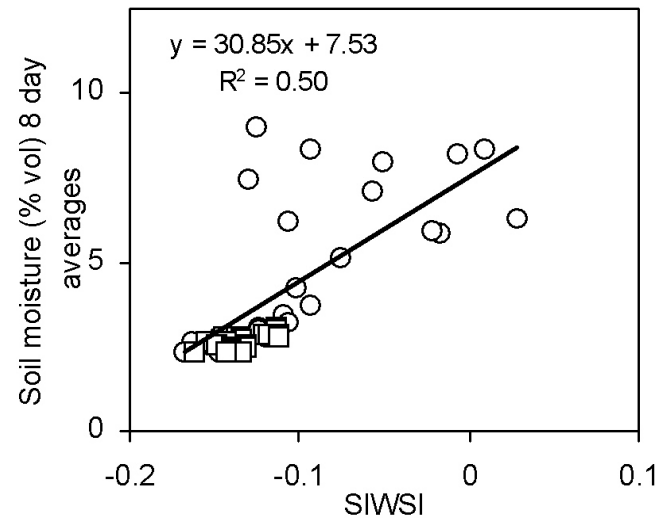

Fig. 5. Linear regression analysis between 8-day values of MODIS SIWSI and 8-day average soil moisture measured at a depth of $5 \mathrm{~cm}$ (soil moisture measurements failed during May and June) for the Demokeya site 2007, January-December (squares denote points outside the growing season).

estimation of $R_{\text {eco }}$ is important with regards to validation of terrestrial carbon models as an erroneous estimate of $\mathrm{R}_{\mathrm{eco}}$ in turn will result in an error in the estimation of GPP. However, a full evaluation of the environmental factors driving respiration at this site and the applicability of the multiplicative model used to derive $\mathrm{R}_{\mathrm{eco}}$ is beyond the scope of this study.

Though the footprint of the flux tower was estimated to be smaller than the $1 \times 1 \mathrm{~km}$ area used for satellite data evaluation, we found strong linear relationships between EVI and NDVI against tower GPP at the Demokeya flux site (Fig. 3). The predictive ability of vegetation indices declined by increasing the window to $3 \times 3$ pixels. Although it may be possible to improve results by integrating footprint source areas over smaller time scales, such as the 8-day periods used by MODIS products, the method used here still illustrates the effect (albeit small in this case) of taking the footprint into account when comparing tower flux measurements against remotely sensed data.

Even if the performance of EVI was only marginally better than NDVI in relation to GPP, several studies have previously reported improved biophysical performance of EVI in comparison to NDVI due to its higher dynamic range, enhanced reduction of atmospheric influences and lower sensitivity to canopy background signals (Miura et al., 2001; Huete et al., 2002; Xiao et al., 2003). In addition, EVI's utility in satellite-driven primary production modeling has previously been demonstrated for several different biome types (Xiao et al., 2004; Rahman et al., 2005; Sims et al., 2006b; Olofsson et al., 2008) and the highly linear relationship observed here clearly suggests that GPP can be estimated through a linear regression model for similar environments with relatively high accuracy, using only EVI as independent variable. 


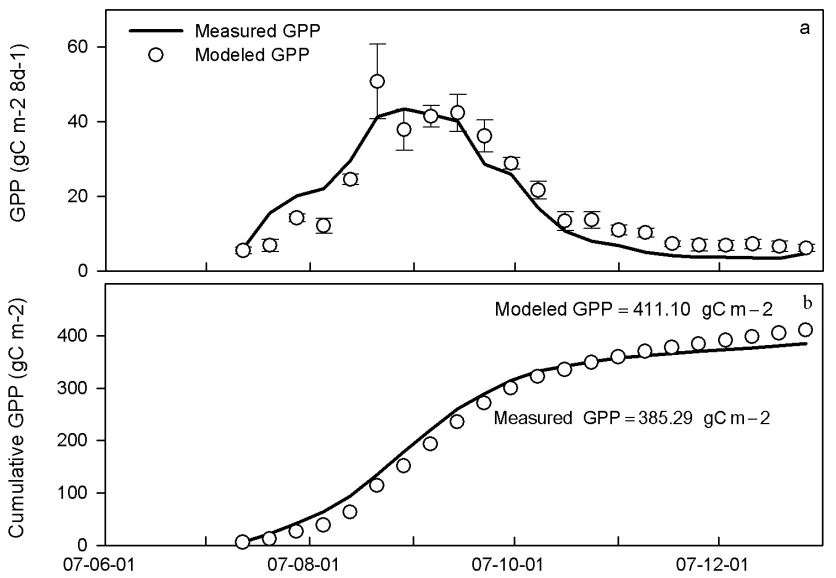

Fig. 6. Seasonal dynamics of (a) 8-day sums of measured eddy covariance GPP and modeled GPP (error bars are the standard deviation of modeled GPP across pixels at individual dates) and (b) measured and modeled cumulative GPP for the Demokeya site 2007, July-December.

We further detected a high correlation between SIWSI and measured tower GPP (Table 1). Although linear regression parameters differed, the strong relationship between SIWSI and both vegetation indices (Fig. 4) indicates that they may measure the same process at this specific site. Similar results have previously been reported with NDVI. For instance, Ceccato et al. $(2001 ; 2002)$ designed a spectral index, the Global Vegetation Moisture Index (GVMI), using NIR, blue and SWIR reflectance data from the VEGETATION sensor onboard the SPOT (Satellite Pour l'Observation de la Terre) satellite. The authors demonstrated that GVMI was fully capable of predicting EWT for localities with complete canopy cover, but comparisons between GVMI and NDVI for savanna regions showed a highly linear relationship (Ceccato and Flasse, 2002). Although Ceccato and Flasse (2002) found similar values of NDVI with different values of GVMI, the authors mention that NDVI could be used to retrieve vegetation water content for some types of species, mainly for those where the degree of senescence is proportional to moisture content, which seems to be the case at the site used in our study. It is however important to mention that SIWSI does require a certain amount of vegetation to be present in order to be useful (Fensholt and Sandholt, 2003). The rather weak correlation between SIWSI and soil moisture (Fig. 5) observed is mainly due to the wide scatter of early growing season points. This indicates that the sparse vegetation cover at the site causes the index to fail as an indicator of water stress. Furthermore, the stronger, but still rather weak relationship observed between both NDVI and EVI against soil moisture could, to some extent, indicate that the effects of water stress are already manifested through the vegetation index signal. Cheng et al. (2006) compared several indices, including SIWSI, NDVI and EVI, to retrievals of EWT from Advanced Visible Infrared Imaging Spectrometer (AVIRIS)

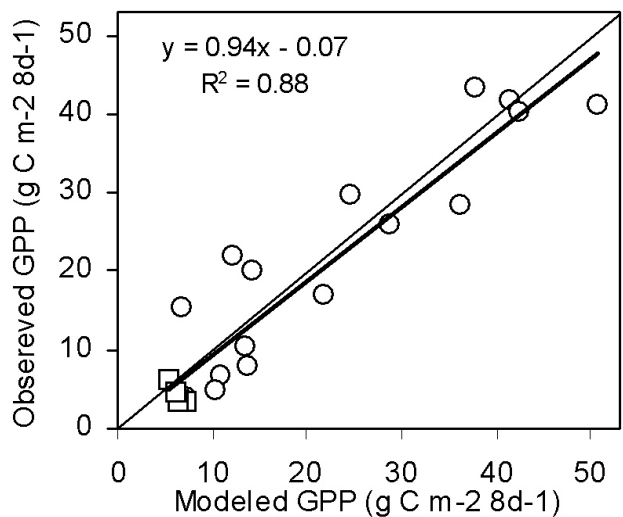

Fig. 7. Linear regression analysis between 8-day sums of measured GPP and modeled GPP for the Demokeya site 2007, JulyDecember (squares denote points outside the growing season).

imagery. The authors showed that EVI had the highest correlation among indices for an agricultural site and a semi-arid savanna shrub site. However, it would have to be further investigated if EVI can mimic the temporal dynamics of EWT at these specific sites as Cheng et al. (2006) further concluded that errors due to soil background reflectance and canopy architecture were inherent in the retrievals of EWT in both the AVIRIS and MODIS data.

Results derived through using EVI and SWISI in a simple parametric LUE-model were shown to agree rather well with measured tower GPP over the 2007 season (Figs. 6 and 7). Although correlations showed that the relationship between EVI and GPP was highly linear (Fig. 3a), there are still a number of factors that influence the vegetation signal recorded at the sensor that in turn can greatly influence the 1:1 relationship assumed between PPAR and EVI in the model. Even though TIMESAT minimizes negatively biased noise due to the interference of clouds and atmospheric constituents, effects of varying solar zenith angles on satellite vegetation index data has previously been shown to be considerable at intermediate Leaf Area Index (LAI) values between 0.25 and 2 (Goward and Huemmrich, 1992). A higher solar zenith angle in the beginning and in the end of the season, tends to increase vegetation index values, whereas a lower solar zenith angle in the middle of the season results in more soil being directly illuminated, thus reducing values. Although the site did show a distinct seasonal variation in EVI and NDVI (Fig. 2d), the applicability of vegetation indices to estimate GPP can still be greatly reduced due to solar angle effects, specifically for sites in semi-arid regions where vegetation is sparse (Sims et al., 2006a). But none of the reflectance values in the $1 \times 1$ window during 2007 were acquired at a solar zenith angle of more than $45^{\circ}$, and as vegetation indices estimated by using red and NIR reflectance are relatively unaffected at solar zenith angles less than $50^{\circ}$ (Goward and Huemmrich, 1992), the effects of solar angle may be minimal. 
The large differences between modeled GPP and observed GPP, specifically for a number of 8-day periods early in the model run (Fig. 6), can be attributed to $\varepsilon$ (i.e. scaled SIWSI) which primarily fails due to the low vegetation cover at the beginning of the growing season. As the water content of the soil gradually increases over time with the first rainfall, the overall albedo of the soil decreases. The reflectance in the SWIR, in turn, rapidly diminishes, causing a peak in the modeled GPP during the middle of the growing season. This rather deceptive temporal pattern of $\varepsilon$ in the early vegetative stage is further enhanced due to scaling. Finally, multiple linear regression analysis confirmed that no significant improvement was obtained by adding $\varepsilon$ to the model (Table 1 ), suggesting that in this case, the parameter is of limited predictive use.

\section{Conclusion}

We have tested the applicability of EVI, NDVI and SIWSI in primary production modeling for semi-arid areas in the Sahel by comparing these indices against field measurements from a site in central Sudan. Both MODIS vegetation indices showed consistent agreement with GPP, with EVI having the highest correlation. Our results suggests that EVI shows significant promise for efficient determination of primary production, and that a simple modeling approach, based solely on EVI, can be utilized to give reliable estimates of GPP at similar ecosystems.

The relation between SIWSI and soil moisture was observed to be moderate, and a comparison between SIWSI and vegetation indices illustrated considerable redundancy, mainly due to similarities in seasonality. Results obtained through multiple linear regression as well as through implementing a simple parametric LUE-model demonstrated that SIWSI did not add further significant explanatory power to measured GPP values. The index failed early in the growing season most likely due to low vegetation cover, leading to the conclusion that its use as a predictor of water stress in similar ecosystems, where vegetation the fraction is low, is restricted. Research using multi-year and site-wide flux tower and climate data sets is however required to further test the use of MODIS indices in satellite data-driven primary production modeling over semi-arid areas in the Sahel.

Acknowledgements. We appreciate the assistance from the Agricultural Research Corporation (ARC) personnel in El Obeid and the assistance from the people of Demokeya during fieldwork. Our thanks also go out to Per Schubert for proofreading the manuscript prior to submission. Finally, the anonymous reviewers are thanked for their useful comments on the manuscript. Economic support was provided by the Swedish National Space Board (contract 120/06), the Swedish Science Council, (contract 2004-3888) and through the EU-funded CARBOAFRICA project.

Edited by: G. Wohlfahrt

\section{References}

Asrar, G., Fuchs, M., Kanemasu, E. T., and Hatfield, J. L.: Estimating Absorbed Photosynthetic Radiation and Leaf Area Index from Spectral Reflectance in Wheat, Agron. J., 76, 300-306, 1984.

Aubinet, M., Grelle, G., Ibrom, A., Rannik, U., Moncrie, J., Foken, T., Kowalski, A. S., Martin, P. H., Berbigier, P., Bernhofer, C., Clement, R., Elbers, J., Granier, A., Grunwald, T., Morgenstern, K., Pilegaard, K., Rebmann, C., Snijders, W., and Valentini, T. R. V.: Estimates of the annual net carbon and water exchange of European forests: the EUROFLUX methodology, Adv. Ecol. Res., 30, 113-175, 2000

Ceccato, P., Flasse, S., Tarantola, S., Jacquemoud, S., and Gregoire, J. M.: Detecting vegetation leaf water content using reflectance in the optical domain, Remote Sens. Environ., 77, 22-33, 2001.

Ceccato, P. and Flasse, S.: Designing a spectral index to estimate vegetation water content from remote sensing data - Part 2. Validation and applications, Remote Sens. Environ., 82, 198-207, 2002.

Ceccato, P., Gobron, N., Flasse, S., Pinty, B., and Tarantola, S.: Designing a spectral index to estimate vegetation water content from remote sensing data: Part 1 - Theoretical approach, Remote Sens. Environ., 82, 188-197, 2002.

Cheng, Y. B., Zarco-Tejada, P. J., Riano, D., Rueda, C. A., and Ustin, S. L.: Estimating vegetation water content with hyperspectral data for different canopy scenarios: relationships between AVIRIS and MODIS indexes, Remote Sens. Environ., 105, 354-366, doi:10.1016/j.rse.2006.07.005, 2006.

Daughtry, C. S. T., Gallo, K. P., and Bauer, M. E.: Spectral estimates of solar radiation intercepted by corn canopies, Agron. J., 75, 527-531, 1983.

Eck, T. F. and Dye, D. G.: Satellite estimation of incident photosynthetically active radiation using ultraviolet reflectance, Remote Sens. Environ., 135-146, 1991.

Eklundh, L. and Olsson, L.: Vegetation index trends for the African Sahel 1982-1999, Geophys. Res. Lett., 30, 1430, doi:10.1029/2002g1016772, 2003.

Fensholt, R. and Sandholt, I.: Derivation of a shortwave infrared water stress index from MODIS near- and shortwave infrared data in a semiarid environment, Remote Sens. Environ., 87, 111121, doi:10.1016/j.rse.2003.07.002, 2003.

Fensholt, R., Sandholt, I., Rasmussen, M. S., Stisen, S., and Diouf, A.: Evaluation of satellite based primary production modelling in the semi-arid Sahel, Remote Sens. Environ., 105, 173-188, doi:10.1016/j.rse.2006.06.011, 2006

Field, C. B., Randerson, J. T., and Malmstrom, C. M.: Global net primary production: combining ecology and remote sensing, Remote Sens. Environ., 51, 74-88, 1995.

Friborg, T., Boegh, E., and Soegaard, H.: Carbon dioxide flux, transpiration and light response of millet in the Sahel, J. Hydrol., 188-189, 633-650, 1997.

Gao, B. C.: NDWI - A normalized difference water index for remote sensing of vegetation liquid water from space, Remote Sens. Environ., 58, 257-266, 1996.

Giles, J.: How to survive a warming world, Nature, 446, 716-717, doi:10.1038/446716a, 2007.

Goward, S. N. and Huemmrich, K. F.: Vegetation canopy PAR absorptance and the normalized difference vegetation index: an assessment using the SAIL model, Remote Sens. Environ., 39, 
119-140, 1992.

Hanan, N. P. and Prince, S. D.: Stomatal conductance of westcentral supersite vegetation in HAPEX-Sahel: Measurements and empirical models, J. Hydrol., 189, 536-562, 1997.

Hanan, N. P., Kabat, P., Dolman, J. A., and Elbers, J. A.: Photosynthesis and carbon balance of a Sahelian fallow savanna, Global Change Biol., 4, 523-538, 1998.

Herrmann, S. M., Anyamba, A., and Tucker, C. J.: Recent trends in vegetation dynamics in the African Sahel and their relationship to climate, Global Environ. Chang., 15, 394-404, doi:10.1016/j.gloenvcha.2005.08.004, 2005.

Hickler, T., Eklundh, L., Seaquist, J. W., Smith, B., Ardö, J., Olsson, L., Sykes, M. T., and Sjöström, M.: Precipitation controls Sahel greening trend, Geophys. Res. Lett., 32, doi:10.1029/2005GL024370, 2005.

Hilker, T., Coops, N. C., Wulder, M. A., Black, T. A., and Guy, R. D.: The use of remote sensing in light use efficiency based models of gross primary production: A review of current status and future requirements, Sci. Total Environ., 404, 411-423, doi:10.1016/j.scitotenv.2007.11.007, 2008.

Houghton, R. A.: Why are estimates of the terrestrial carbon balance so different?, Global Change Biol., 9, 500-509, 2003.

Huete, A., Liu, H. Q., and van Leeuwen, W. J. D.: The use of vegetation indices in forested regions: issues of linearity and saturation, Geoscience and Remote Sensing, 1997. IGARSS '97. "Remote Sensing - A Scientific Vision for Sustainable Development", 1997 IEEE International, 4, 1966-1968, 1997.

Huete, A., Didan, K., Miura, T., Rodriguez, E. P., Gao, X., and Ferreira, L. G.: Overview of the radiometric and biophysical performance of the MODIS vegetation indices, Remote Sens. Environ., 83, 195-213, 2002.

Hulme, M.: Climatic perspectives on Sahelian desiccation: 19731998, Global Environ. Chang., 11, 19-29, 2001.

IPCC: Summary for policymakers, in: Climate Change 2007: The Physical Science Basis. Contribution of Working Group I to the Fourth Assessment Report of the Intergovernmental Panel on Climate Change, edited by: Solomon, S., Qin, D. Manning,, M., Chen, Z., Marquis, M., Averyt, K. B., Tignor, M., and Miller, H. L., Cambridge, UK and New York, NY, USA, 2007.

Jönsson, P. and Eklundh, L.: Seasonality extraction by function fitting to time-series of satellite sensor data, IEEE T. Geosci. Remote, 40, 1824-1832, doi:10.1109/TGRS.2002.802519, 2002.

Jönsson, P. and Eklundh, L.: TIMESAT - a program for analyzing time-series of satellite sensor data, Comput. Geosci., 833-845, doi:10.1016/j.cageo.2004.05.006, 2004.

Justice, C. O., Townshend, J. R. G., Vermote, E. F., Masuoka, E., Wolfe, R. E., Saleous, N., Roy, D. P., and Morisette, J. T.: An overview of MODIS Land data processing and product status, Remote Sens. Environ., 83, 3-15, 2002.

Liang, S. L., Zheng, T., Liu, R. G., Fang, H. L., Tsay, S. C., and Running, S.: Estimation of incident photosynthetically active radiation from Moderate Resolution Imaging Spectrometer data, J. Geophys. Res.-Atmos., 111, D15208, doi:10.1029/2005jd006730, 2006.

Lloyd, J. and Taylor, J. A.: On the temperature dependence of soil respiration, Funct. Ecol., 8, 315-323, 1994.

Miura, T., Huete, A. R., Yoshioka, H., and Holben, B. N.: An error and sensitivity analysis of atmospheric resistant vegetation indices derived from dark target-based atmospheric correction,
Remote Sens. Environ., 78, 284-298, 2001.

Monteith, J. L.: Solar radiation and productivity in tropical ecosystems, J. Appl. Ecol., 9, 747-766, 1972.

Monteith, J. L.: Climate and the efficiency of crop production in Britain, Philosophical Transactions of the Royal Society of London, Series B, Biol. Sci., 281, 277-294, 1977.

Nemani, R. R. and Running, S. W.: Estimation of regional surface resistance to evapotranspiration from NDVI and thermal-IR AVHRR data, J. Appl. Meteorol., 28, 276-284, 1989.

Olofsson, P., Eklundh, L., Lagergren, F., Jönsson, P., and Lindroth, A.: Estimating net primary production for Scandinavian forests using data from Terra/MODIS, Adv. Space Res., 39, 125-130, doi:10.1016/j.asr.2006.02.031, 2007a.

Olofsson, P., Van Laake, P. E., and Eklundh, L.: Estimation of absorbed PAR across Scandinavia from satellite measurements Part I: Incident PAR, Remote Sens. Environ., 110, 252-261, doi:10.1016/j.rse.2007.02.021, 2007b.

Olofsson, P., Lagergren, F., Lindroth, A., Lindström, J., Klemedtsson, L., Kutsch, W., and Eklundh, L.: Towards operational remote sensing of forest carbon balance across Northern Europe, Biogeosciences, 5, 817-838, 2008, http://www.biogeosciences.net/5/817/2008/.

Prince, S. D. and Goward, S. N.: Global primary production: A remote sensing approach, J. Biogeogr., 22, 815-835, 1995.

Rahman, A. F., Sims, D. A., Cordova, V. D., and El-Masri, B. Z.: Potential of MODIS EVI and surface temperature for directly estimating per-pixel ecosystem C fluxes, Geophys. Res. Lett., 32, L19404, doi:10.1029/2005GL024127, 2005.

Reichstein, M., Falge, E., Baldocchi, D., Papale, D., Aubinet, M., Berbigier, P., Bernhofer, C., Buchmann, N., Gilmanov, T., Granier, A., Grunwald, T., Havrankova, K., Ilvesniemi, H., Janous, D., Knohl, A., Laurila, T., Lohila, A., Loustau, D., Matteucci, G., Meyers, T., Miglietta, F., Ourcival, J.-M., Pumpanen, J., Rambal, S., Rotenberg, E., Sanz, M., Tenhunen, J., Seufert, G., Vaccari, F., Vesala, T., Yakir, D., and Valentini, R.: On the separation of net ecosystem exchange into assimilation and ecosystem respiration: review and improved algorithm, Global Change Biol., 11, 1424-1439, doi:10.1111/j.13652486.2005.001002.x, 2005.

Schmid, H. P.: Source areas for scalars and scalar fluxes, Bound.Layer Meteor., 67, 293-318, 1994.

Seaquist, J. W. and Olsson, L.: Rapid estimation of photosynthetically active radiation over the West African Sahel using the Pathfinder Land Data Set, Int. J. Appl. Earth Obs., 1, 205-213, 1999.

Seaquist, J. W., Olsson, L., and Ardo, J.: A remote sensing-based primary production model for grassland biomes, Ecol. Model., 169, 131-155, doi:10.1016/S0304-3800(03)00267-9, 2003.

Seaquist, J. W., Olsson, L., and Eklundh, L.: Broad-scale increase in NPP quantified for the African Sahel, 1982-1999, Int. J. Remote Sens., 5115-5122, doi:10.1080/01431160600868458, 2006.

Sellers, S. J., Tucker, C. J., Collatz, G. J., Los, S. O., Justice, C. O., Dazlich, D. A., and Randall, D. A.: A global 1degrees by 1-degrees NDVI data set for climate studies. Part 2: The generation of global fields of terrestrial biophysical parameters from the NDVI, Int. J. Remote Sens., 15, 3519-3545, doi:10.1016/j.rse.2005.01.020, 1994.

Sims, D. A., Luo, H. Y., Hastings, S., Oechel, W. C., Rahman, A. F., and Gamon, J. A.: Parallel adjustments in vegetation greenness 
and ecosystem $\mathrm{CO}_{2}$ exchange in response to drought in a Southern California chaparral ecosystem, Remote Sens. Environ., 103, 289-303, doi:10.1016/j.rse.2005.01.020, 2006a.

Sims, D. A., Rahman, A. F., Cordova, V. D., El-Masri, B. Z., Baldocchi, D. D., Flanagan, L. B., Goldstein, A. H., Hollinger, D. Y., Misson, L., Monson, R. K., Oechel, W. C., Schmid, H. P., Wofsy, S. C., and Xu, L. K.: On the use of MODIS EVI to assess gross primary productivity of North American ecosystems, J. Geophys. Res. (G. Biogeosci.), 111, G04015, doi:10.1029/2006JG000162as, 2006b.

Sims, D. A., Rahman, A. F., Cordova, V. D., El-Masri, B. Z., Baldocchi, D. D., Bolstad, P. V., Flanagan, L. B., Goldstein, A. H., Hollinger, D. Y., Misson, L., Monson, R. K., Oechel, W. C., Schmid, H. P., Wofsy, S. C., and Xu, L.: A new model of gross primary productivity for North American ecosystems based solely on the enhanced vegetation index and land surface temperature from MODIS, Remote Sens. Environ., 112, 1633-1646, doi:10.1016/j.rse.2007.08.004, 2008.

Sitch, S., Smith, B., Prentice, I. C., Arneth, A., Bondeau, A., Cramer, W., Kaplan, J. O., Levis, S., Lucht, W., Sykes, M. T., Thonicke, K., and Venevsky, S.: Evaluation of ecosystem dynamics, plant geography and terrestrial carbon cycling in the LPJ dynamic global vegetation model, Global Change Biol., 9, 161$185,2003$.

Tucker, C. J.: Red and photographic infrared linear combinations for monitoring vegetation, Remote Sens. Environ., 8, 127-150, 1979.
Tucker, C. J., Vanpraet, C., Boerwinkel, E., and Gaston, A.: Satellite remote sensing of total dry matter production in the Senegalese Sahel, Remote Sens. Environ., 13, 461-474, 1983.

Tucker, C. J., Vanpraet, C. L., Sharman, M. J., and Van Ittersum, G.: Satellite remote sensing of total herbaceous biomass production in the Senegalese Sahel: 1980-1984, Remote Sens. Environ., 17, 233-249, 1985.

Van Laake, P. E. and Sanchez-Azofeifa, G. A.: Mapping PAR using MODIS atmosphere products, Remote Sens. Environ., 94, 554563, doi:10.1016/j.rse.2004.11.011, 2005.

Vermote, E. F., El Saleous, N. Z., and Justice, C. O.: Atmospheric correction of MODIS data in the visible to middle infrared: first results, Remote Sens. Environ., 83, 97-111, 2002.

Wang, Y.-P. and Leuning, R.: A two-leaf model for canopy conductance, photosynthesis and partitioning of available energy I: Model description and comparison with a multi-layered model, Agr. Forest. Meteorol., 91, 89-111, 1998.

Wieringa, J.: Representative roughness parameters for homogeneous terrain, Bound.-Layer Meteor., 63, 323-363, 1993.

Xiao, X. M., Braswell, B., Zhang, Q., Boles, S., Frolking, S., and Moore, B.: Sensitivity of vegetation indices to atmospheric aerosols: continental-scale observations in Northern Asia, Remote Sens. Environ., 84, 385-392, 2003.

Xiao, X. M., Hollinger, D., Aber, J., Goltz, M., Davidson, E. A., Zhang, Q., and Moore, B.: Satellite-based modeling of gross primary production in an evergreen needleleaf forest, Remote Sens. Environ., 89, 519-534, doi:10.1016/j.rse.2003.11.008, 2004. 